\title{
Ozone and temperature decadal solar-cycle responses, and their relation to diurnal variations in the stratosphere, mesosphere, and lower thermosphere, based on measurements from SABER on TIMED
}

\author{
Frank T. Huang ${ }^{1, *}$ and Hans G. Mayr ${ }^{2, *}$ \\ ${ }^{1}$ University of Maryland, Baltimore County, MD 21250, USA \\ ${ }^{2}$ NASA Goddard Space Flight Center, Greenbelt, MD 20771, USA \\ * retired
}

Correspondence: Frank T. Huang (fthuang@ verizon.net)

Received: 10 March 2019 - Discussion started: 18 March 2019

Revised: 4 June 2019 - Accepted: 5 June 2019 - Published: 2 July 2019

\begin{abstract}
There is evidence that the ozone and temperature responses to the solar cycle of $\sim 11$ years depend on the local times of measurements. Here we present relevant results based on SABER data over a full diurnal cycle, which were not previously available. In this area, almost all satellite data used are measured at only one or two fixed local times, which can differ among various satellites. Consequently, estimates of responses can be different depending on the specific data set. Furthermore, over years, due to orbital drift, the local times of the measurements of some satellites have also drifted. In contrast, SABER makes measurements at various local times, providing the opportunity to estimate diurnal variations over $24 \mathrm{~h}$. We can then also estimate responses to the solar cycle over both a diurnal cycle and at the fixed local times of specific satellite data for comparison. Responses derived in this study, based on zonal means of SABER measurements, agree favorably with previous studies based on data from the HALOE instrument, which only measured data at sunrise and sunset, thereby supporting the analysis of both studies. We find that for ozone above $\sim 40 \mathrm{~km}$, zonal means reflecting specific local times (e.g., 6, 12, 18, 24 LST - local solar time) lead to different values of responses, and to different responses based on zonal means that are also averages over the $24 \mathrm{~h}$ local time period, as in 3-D models. For temperature, the effects of diurnal variations on the responses are not negligible even at $\sim 30 \mathrm{~km}$ and above. We also considered the consequences of local time variations due to orbital drifts of certain operational satellites, and, for both ozone and
\end{abstract}

temperature, their effects can be significant above $\sim 30 \mathrm{~km}$. Previous studies based on other satellite data do not describe the treatment, if any, of local times. Some studies also analyzed data merged from different sources, with measurements made at different local times. Generally, the results of these studies do not agree very well among themselves. Although responses are a function of diurnal variations, this is not to say that they are the major reason for the differences, as there are likely other data-related issues. The effects due to satellite orbital drift may explain some unexpected variations in the responses, especially above $40 \mathrm{~km}$.

\section{Introduction}

The understanding of the response of atmospheric ozone and temperature to the solar cycle of $\sim 11$ years is important for both scientific and practical reasons. Global responses in the stratosphere, mesosphere, and lower thermosphere have been investigated over decades based on a variety of satellite data.

There is evidence that the magnitude of responses to decadal solar cycles depends on the local times at which the measurements are made. For example, Beig et al. (2012), in analyzing data from the Halogen Occultation Experiment (HALOE), found that derived responses are different at sunrise (6 LST) and sunset (18 LST). 
However, with a few exceptions, the instruments on satellites only measure at one or two local times, which are fixed for the entire mission.

Generally, previous studies do not address the issue of diurnal variations of the responses in detail, and there have been no studies describing the variations of the responses over the $24 \mathrm{~h}$ local time period. In the following, we provide estimates of the diurnal variations of the responses over a $24 \mathrm{~h}$ period, which was previously not available.

As noted in Huang et al. (2016b), previous global responses to the 11-year solar cycle based on measurements have been largely based on data from the NOAA operational satellites, including the Stratosphere Sounding Unit (SSU), the Microwave Sounding Unit (MSU), and the Solar Backscatter Ultraviolet (SBUV) instruments; from the Stratospheric Aerosol and Gas Experiment (SAGE I, II) on the Explorer and Earth Radiation Budget (ERB) satellites; from the Halogen Occultation Experiment (HALOE) on the Upper Atmosphere Research Satellite (UARS); and from the Sounding of the Atmosphere using Broadband Emission Radiometry (SABER) instrument on the ThermosphereIonosphere-Mesosphere-Energetics and Dynamics (TIMED) satellite, among others. The advantage of the operational satellites is that they can provide global measurements covering decades, and can be replaced as needed. However, issues regarding instrument offsets, stability, and continuity over many years and decades can be problematic.

Except for SABER (and UARS), instruments on these satellites only make measurements at one or two local times, which are fixed for the mission duration. The NOAA operational satellites are sun-synchronous, in which case the measurements are made at two fixed local times: one for the ascending orbital mode and one for the descending mode. HALOE and SAGE only make solar occultation measurements at instrument sunrise and sunset. Consequently, used as is, responses based on zonal means of the above measurements reflect long-term variations at the fixed local times, and could be a source of differences among the various studies.

They could also be a source of differences with 3-D models, in which ozone amounts and temperature vary with local time around a latitude circle, and zonal means are averages over both longitude and a $24 \mathrm{~h}$ local time period. When comparing the results of responses based on zonal means from measurements with models, Austin et al. (2008) pointed out that "The model results are strictly zonal average values, which is an average over local time, whereas the observations are typically made at fixed local times. Therefore, in the mesosphere, where the diurnal variation of ozone is large, some of the differences between model results and observations may have arisen from a diurnal variation in the actual solar response". See also Beig et al. (2012).

In addition, the orbits of some operational satellites have drifted, so that the local times at which the measurements are made have also drifted over several hours or more (see
McPeters et al., 2013; Frith et al., 2014; Remsberg, 2008; Randel et al., 2009; Tummon et al., 2015; Hood et al., 2015). Tummon et al. (2015) summarizes some of the data processing methods used by various groups. Generally, they report that diurnal variations are either neglected, or are assumed to be negligible below 45-50 km (see also Davis et al., 2016).

Previous results have not generally agreed so well with one another with respect to their details. A major reason for these differences may be the conditions and constraints under which the various measurements were made (for details, see Austin et al., 2008; Crooks and Gray 2005, Gray et al., 2005, and Huang et al., 2016b).

In addition, previous studies have generally not described how they treat diurnal variations, so that comparisons related to responses as a function of local times are problematic. We are also not aware of studies based on orbital drift.

In contrast to most other measurements, SABER provides additional information which allows us to estimate daily ozone and temperature diurnal variations, and, in turn, the dependence of their responses to the decadal solar cycle on local time. In the following, we focus on zonal means of ozone and temperature, either at various specific local times, or averaged over local times (as in a 3-D model), and the effects of their diurnal variations on their responses to solar variability over a solar cycle of $\sim 11$ years (2002-2014), from 20 to $100 \mathrm{~km}$.

In this study, we find that not only do the values of the responses depend on the local times at which the measurements are made, but they can be significant even at altitudes as low as $30 \mathrm{~km}$.

In Sect. 2, we review our previous analysis and derivation of diurnal variations and zonal means that are averages of both longitude and local time around a latitude circle, based on SABER measurements. We also describe how we can estimate new results of zonal means corresponding to specific local times, and new results estimating the effects of orbital drift on diurnal variations. In Sect. 3 we describe our new results of responses to the solar cycle at the specific local times of sunrise (6 LST) and sunset (18LST), and compare them with results from HALOE. This gives an indication of the quality and reality of both sets of results. In Sect. 4 we describe our new results for responses to the solar cycle over a diurnal cycle of $24 \mathrm{~h}$. In Sect. 5 we describe our estimates of responses in situations where the local times have "drifted" due to satellite orbital drifts. We also describe some previous studies. In Sect. 6 we discuss the issue of data length.

\section{SABER data characteristics and analysis}

The SABER/TIMED instrument (Russell et al., 1999) was launched in December 2001 with an orbital inclination of $74^{\circ}$. SABER views the Earth's limb to the side of the orbital plane, and vertical profiles, corresponding to the line-of-sight tangent point, are retrieved from measurements of the $\mathrm{CO}_{2}$ 
15 and $4.3 \mu \mathrm{m}$ emissions for kinetic temperature, and from the $9.6 \mu \mathrm{m}$ channel for ozone. About every $60 \mathrm{~d}$, TIMED is yawed by $180^{\circ}$, so that the SABER measurement footprint spans the latitudes from $\sim 83^{\circ} \mathrm{N}$ to $52^{\circ} \mathrm{S}$ or $\sim 83^{\circ} \mathrm{S}$ to $52^{\circ} \mathrm{N}$ on alternate yaw periods. Over a given day and for a given latitude circle, measurements are made as the satellite travels northward (ascending mode) and again as the satellite travels southward (descending mode). Data at different longitudes are sampled over $1 \mathrm{~d}$ as the Earth rotates relative to the orbital plane.

SABER scans altitude ( 10-105 km for temperature, $15-$ $100 \mathrm{~km}$ for ozone) every $58 \mathrm{~s}$ with an altitude resolution of $\sim 2 \mathrm{~km}, \sim 96$ scans per orbit, and $\sim 14$ longitudes per day.

The orbital characteristics of the satellite are such that, over a given day, a given latitude circle, and a given orbital mode (ascending or descending), the local time at which the data are measured is essentially the same, independent of longitude and time of day. For a given day, latitude, and altitude, we work with data averaged over longitude: one for the ascending orbital mode and one for the descending mode, each corresponding to a different local solar time, resulting in two data points for each day. Each can be biased by the local time variations and is therefore not a true zonal mean. True zonal means are averages made at a specific time over longitude around a latitude circle, with the local solar time varying by $24 \mathrm{~h}$ over $360^{\circ}$ of longitude. The local times of the SABER measurements decrease by about $12 \mathrm{~min}$ from day to day, and it takes $\sim 60 \mathrm{~d}$ to sample over the $24 \mathrm{~h}$ of local time.

\subsection{Previous analysis}

The data are provided by the SABER project (version 2.0, Level 2A). They are interpolated to $4^{\circ}$ latitude and $2.5 \mathrm{~km}$ altitude grids, after which zonal averages are taken for analysis.

In contrast to other satellite measurements, those from SABER (Russell III et al., 1999) contain information that allows for the estimation of the diurnal variations of ozone and temperature, and the results are described in Huang et al. (2010a, b).

As noted in Huang et al. (2016b), SABER ozone and temperature measurements have been analyzed with success for more than a decade. We have derived variations with periods from 1 day or less (diurnal variations) up to multiple years (semiannual oscillations - SAO, and quasi-biennial oscillations - QBO), and 1 decade or more (trends and responses to solar cycle)(see Huang et al., 2008a, b; 2010a, b; 2014; 2016a, b). Zhang et al. (2006) and Mukhtarov et al. (2009) have derived temperature diurnal tides using SABER data, and Nath and Sridharan (2014) have also derived responses to solar variability using SABER data.

For both ozone and temperature, these studies show that, for variations that are deviations from a mean state (e.g., diurnal variations, tides, semiannual and quasi-biennial oscillations, and responses to solar variability and trends), SABER measurements are robust and precise. For example, zonal mean tidal temperatures can agree with other measurements to within $\sim 1 \mathrm{~K}$ (Huang et al., 2010a), and our zonal mean ozone diurnal variations can agree with other diurnal measurements within less than a few percent (Huang et al., 2010b).

These previous results contain diurnal variations of ozone and temperature for each day of the year, and zonal means that are averages over both longitude and local time in a consistent manner, which can then be compared directly with 3-D models.

These previous results contain

1. diurnal variations of ozone and temperature for each day of the year, and

2. zonal means that are averages over both longitude and local time in a consistent manner, which can then be compared directly with 3-D models.

Using these results, we can then estimate the goals of this study, which are as follows:

3. to reconstruct the zonal means to reflect specific local times;

4. to calculate responses to solar variability over a solar cycle at specific local times;

5. and to estimate local time variations of responses as a result of orbital drifts of NOAA satellites, as noted above.

Hence, we can find the variation of responses to the solar cycle over the $24 \mathrm{~h}$ local time period, including at 6 and $18 \mathrm{LST}$ for comparison with responses based on HALOE data at sunrise and sunset (see Beig et al., 2012; Fadnavis and Beig, 2006).

Compared with the stratosphere, diurnal variations of ozone and temperature themselves are more prominent in the mesosphere and lower thermosphere. Even in the stratosphere, they may not be negligible (Huang et al., 2010a, b). Between $\sim 30$ and $80 \mathrm{~km}$, ozone diurnal variations are mainly due to photochemistry (Brasseur and Solomon, 2005), whereas temperature diurnal variations are mainly a result of thermal tides (Chapman and Lindzen, 1970). For diurnal variations, our results for both ozone and temperature (Huang et al., 2010a, b) show that they can be systematic from the lower thermosphere down to $25 \mathrm{~km}$. This is consistent with results by Sakazaki et al. (2015) for ozone, and Oberheide et al. (2000) and Gille et al. (1991) for temperature.

As discussed below, for responses due to the solar cycle, our results show that the effects of local time variations can be non-negligible, even for altitudes below $40 \mathrm{~km}$, especially for temperature. 


\subsubsection{Diurnal variations}

As noted above, and in Huang et al. (2016b), unlike other satellites mentioned above (except UARS), the orbital characteristics of TIMED are such that SABER samples over the $24 \mathrm{~h}$ local time period, which can be used to estimate diurnal variations of ozone and temperature. A complication is that it takes SABER $60 \mathrm{~d}$ to sample over the $24 \mathrm{~h}$ local time period. Over $60 \mathrm{~d}$, the variations with local time are embedded with the seasonal variations, and need to be separated from them. The method we use estimates both the diurnal and mean variations (e.g., seasonal, semiannual, and annual) together, by performing a least squares fit of a 2-D Fourier series, where the independent variables are local time and day of year. The algorithm is discussed further in Huang et al. (2010a, b).

The top row of Fig. 1 shows zonal mean ozone diurnal variations (percent deviation from midnight) for day 85 of 2005, at the Equator, from 25 to $40 \mathrm{~km}$ (Fig. 1a), 45 to $60 \mathrm{~km}$ (Fig. 1b), based on SABER data (see Huang et al., 2010b for details, and references). It can be seen that diurnal variations can be significant even at $25 \mathrm{~km}$. Since the study of Huang et al. (2010b), Sakazaki et al. (2013) have derived comprehensive ozone diurnal variations based on observations from the Superconducting SubmillimeterWave Limb-Emission Sounder (SMILES) on board the International Space Station (ISS).

Figure 1c and d correspond to Fig. 1a and b, but for temperature (see Huang et al., 2010a for details). Even at altitudes near $30 \mathrm{~km}$, the diurnal variations are systematic and, as seen below, can affect results when estimating decadal responses. Although small, at $30 \mathrm{~km}$, the diurnal variations of temperature compare well with Zeng et al. (2008), Oberheide et al. (2000), and Gille et al. (1991), based on different types of measurements.

\subsubsection{Mean variations}

Once the diurnal variations are known for each day, the zonal mean variations, which are averages over longitude and local time, consistent with 3-D models, can be obtained.

Based on these zonal means, our earlier results of decadal responses to solar activity, as represented by the $10.7 \mathrm{~cm}$ solar flux, have been presented in Huang et al. (2016a, b).

\subsection{Current analysis}

\subsubsection{Multiple regression}

For the current study, as for the previous analysis, we generate diurnal variations and mean variations, from which we generate the following:

a. monthly zonal means that are averaged over longitude, but at specific local times. These correspond to those satellite measurements which sample at specific local times; b. zonal means with local times that vary from month to month, to simulate the situation caused by satellite orbital drifts, as described earlier;

c. and estimates of responses to the solar cycle, based on (a) and (b), and compared with responses based on zonal means that are also averaged over local time.

As an example, Fig. 2a shows our ozone monthly mean mixing ratios (red line, parts per million by volume - ppmv) at $47.5 \mathrm{~km}$ and at the Equator, from mid 2002 to mid 2014, with seasonal and local time variations removed. The green lines represents how the data would vary if we simulated the variations with local time due to orbital drifts of the NOAA operational satellites. We have varied the local times such that from 2002 to 2014, they progress from 12 to 18 LST. The corresponding $10.7 \mathrm{~cm}$ flux is also shown (black lines, right axis, units in sfu). As can be seen, 2002 was near solar maximum (the middle of solar cycle 23), and 2014 is some years into cycle 24 , which began in $\sim 2008$. Figure $2 \mathrm{~b}$ corresponds to Fig. 2a, but for temperature (K) at $45 \mathrm{~km}$. The labels "CRC" denote the correlation coefficients between the respective ozone and temperature zonal means and the $10.7 \mathrm{~cm}$ flux.

The estimates of responses to the solar cycle are made using Eq. (1), in a similar manner as previously undertaken by others, and by us, using a multiple regression analysis (e.g., Keckhut et al., 2005; Soukharev and Hood, 2006; Huang et al., 2016b) that includes solar activity, trends, seasonal, quasi-biennial oscillations (QBO), and local time terms, among others, on monthly values. Specifically, the estimates are found from the following equation:

$$
\begin{aligned}
M(t) & =a+b \cdot t+d \cdot \mathrm{F} 107(t)+c \cdot S(t) \\
& +l \cdot 1 \operatorname{st}(t)+g \cdot \mathrm{QBO}(t),
\end{aligned}
$$

where $t$ is time (months), $a$ is a constant, $b$ is the trend, $d$ the coefficient for solar activity $(10.7 \mathrm{~cm}$ flux $), c$ is the coefficient for the seasonal variations $(S(t)), l$ the coefficient for local time variations (lst), and $g$ is the coefficient for the QBO. As is often done, the seasonal and local time variations are removed first, but we include them in Eq. (1) for completeness. F107 stands for the solar $10.7 \mathrm{~cm}$ flux, which is commonly used as a measure of solar activity, and the values used here are monthly means provided by NOAA.

$M(t)$ stands for the input ozone or temperature zonal means described in (a) and (b) in this section.

The algorithm is applied to the monthly zonal-mean values from June 2002 through June 2014 (as in Fig. 2), from $48^{\circ} \mathrm{S}$ to $48^{\circ} \mathrm{N}$ latitude, and from 20 to $100 \mathrm{~km}$ altitude.

\subsubsection{Statistical and error considerations}

The analysis of uncertainties is the same for the current study as for the previous study of the mean variations described above. It is only the input data that are different. Previously, the input consisted of zonal means that were averaged 

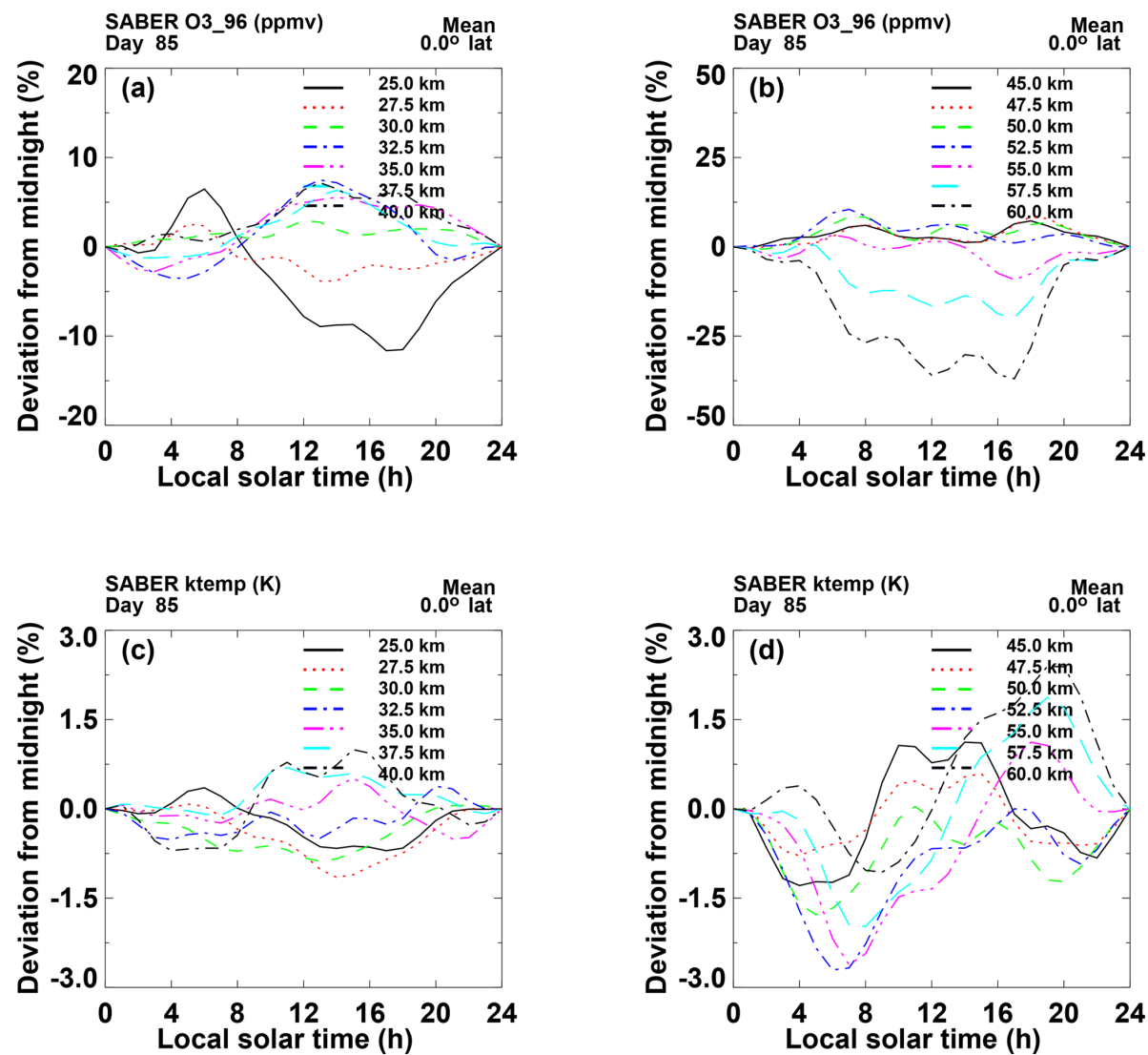

Figure 1. (a, b) Ozone zonal mean mixing ratios (ppmv) versus local time for day 05085 at the Equator. (a) At 25 to $40 \mathrm{~km}$ (percent deviation from midnight) and (b) 45 to $60 \mathrm{~km}$. (c, d) As in (a, b), but for temperature (K).

over both longitude and local time, as in 3-D models. Here the zonal mean reflects measurements made at specific local times. Details of the statistical analysis are given in Huang et al. (2016a, b).

The studies use a least squares fit of the multiple regression of Eq. (1). Uncertainties in the responses are found from the sample variance (Bevington and Robinson, 1992; Huang et al., 2016a) of the fit. The curvature matrix and its inversion are quite stable due to the excellent sampling of SABER, as there are essentially no significant data dropouts to speak of. Therefore, the standard errors are quite stable and reasonable, as can be seen by the error bars in Figs. 6, 7, 8, and Figs. A1 and A2 in the Appendix. Although very stable in our case, the inversion of the curvature matrix does not explicitly or definitively address potential aliasing among the various terms of the multiple regression, unless the matrix is diagonal.

In Sect. 6 (Data length and aliasing) below, we show that the derived responses are essentially the same whether we use all of the terms in Eq. (1) or only the term containing the solar flux to obtain the responses. Hence, aliasing is not an issue here.

\section{Results}

\subsection{Ozone and temperature responses to solar cycle at 6 and 18 LST (sunrise and sunset)}

We use the term "response to solar activity (solar cycle)" to refer to $d \cdot \mathrm{F} 107$ in Eq. (1), and, in particular, to ozone or temperature responses at solar maximum minus those at solar minimum, per 100 solar flux units (sfu). For ozone, it is also in terms of percentage differences. A positive response means that the response at solar maximum is larger than that at solar minimum (Huang et al., 2016b).

For the new results of this study, we focus on the following:

1. responses to the solar cycle at 6 and 18 LST (sunrise, sunset) - specifically comparisons with responses based on HALOE data (Beig et al., 2012; Fadnavis and Beig, 2006), which measure only at sunrise and sunset;

2. responses based on zonal means at specific local times;

3. responses with local times changing due to satellite orbital drifts; 

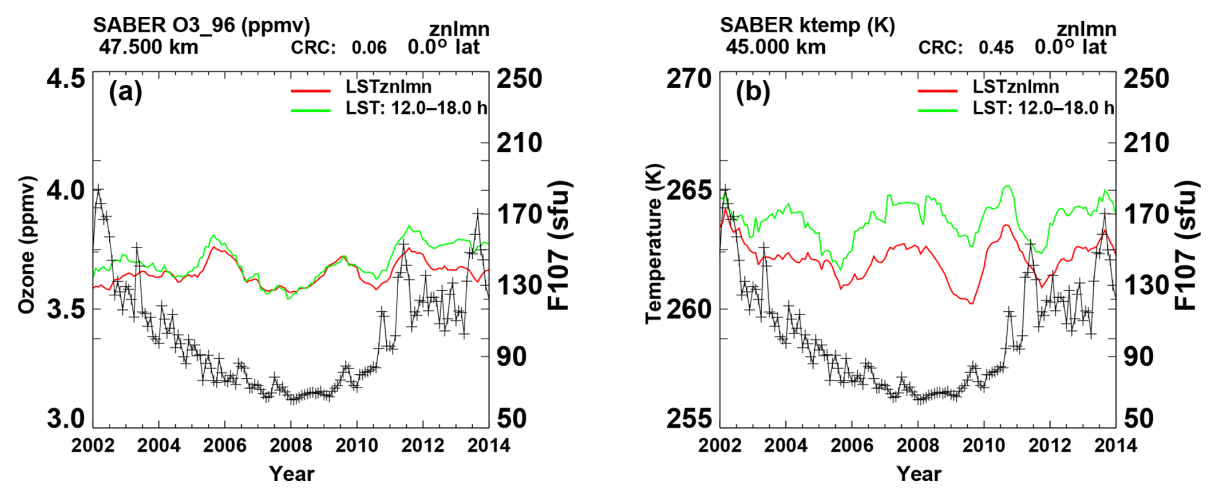

Figure 2. Ozone zonal mean mixing ratios (a, red line, ppmv) from mid 2002 to mid $2014,47.5 \mathrm{~km}, 0^{\circ}$; (b), as in (a), but for temperature $(\mathrm{K})$ at $45 \mathrm{~km}$. The green lines represent how the data would vary if we simulated the variations with local time due to simulated orbital drifts of the NOAA operational satellites. Black lines (+, right axis) show the corresponding monthly $10.7 \mathrm{~cm}$ flux (sfu) provided by NOAA.

4. and comparison with results based on zonal means that are averages over both longitude and local time simultaneously, as in 3-D models.

\subsection{Ozone responses at 6 and 18 LST (sunrise and sunset)}

We first consider sunrise and sunset (6 and 18 LST, respectively) because we can compare these data with direct empirical results from Beig et al. (2012) and Fadnavis and Beig (2006), based on HALOE data from January 1992 to November 2005. Importantly, unlike other studies, they describe how they treat variations with local times, although they only present results at 6 and 18 LST.

The comparisons will indicate the quality of our results at 6 and 18 LST, and also over the $24 \mathrm{~h}$ local time period.

In Fig. 3 and other applicable figures, we have manually transferred values of plots from other studies for comparison; hence, they are not exact, but should be adequate for our purposes.

In comparisons with results based on HALOE data, uncertainties should be considered. According to Beig et al. (2012) and Fadnavis and Beig (2006), due to the sparse sampling inherent in solar occultation measurements, there are only 8 to 12 data points (sometimes less) per month for each latitude. Therefore, they generally present responses that are based on data composited over $30^{\circ}$ latitude bins (e.g., $0-30^{\circ} \mathrm{S}, \mathrm{N}$ ) and averages of responses at sunrise and sunset. We present results at $4^{\circ}$ intervals. Even if we composite the SABER data into $30^{\circ}$ bins, the distribution within the bins would be uniform, but quite different than that of HALOE data; hence, we will present our results at specific latitudes. Our responses can vary significantly as a function of latitude, so that is another consideration in the comparisons.

In addition, in this paper and in the literature, ozone responses are normally given in terms of percent changes, and the value of the ozone itself is needed to get percent val- ues. Because absolute values among various instruments can sometimes be offset, it is an added source of uncertainty.

Figure 3a shows ozone responses from 50 to $100 \mathrm{~km}$, at $4^{\circ} \mathrm{N}$ from this study and from Beig et al. (2012). The magenta triangles show responses based on HALOE data for ozone (composite, $0-30^{\circ} \mathrm{N}$, BEIGN), which are averages of sunrise and sunset responses, and should be compared with the red plusses, which denote the average of our results at 6 and 18 LST. It can be seen that the agreement between the averages (magenta triangles and red plusses) is very favorable, except for our large negative value at $77.5 \mathrm{~km}$, and values above $90 \mathrm{~km}$. The green asterisks denote our results for 6LST and the blue diamonds denote our responses at $18 \mathrm{LST}$. Figure $3 \mathrm{~b}$ corresponds to Fig. $3 \mathrm{a}$, but for $20^{\circ} \mathrm{N}$ and 20 to $60 \mathrm{~km}$, and the HALOE results are from Fadnavis and Beig (2006), $0-30^{\circ} \mathrm{N}$ composite. As in Fig. 3a, the agreement with our averages (magenta triangles and red plusses) is very favorable. It can be seen that even in the stratosphere, the responses at $6 \mathrm{LST}$ are different from those at $18 \mathrm{LST}$.

Considering our discussion of the uncertainties above, we believe that the results of Beig et al. (2012) and Fadnavis and Beig (2006) (magenta triangles), agree very well with our estimates (red plusses) in both altitude ranges (Fig. 3a, b): note in particular the rapid change from negative to positive values near $75-80 \mathrm{~km}$. In Fig. $3 \mathrm{a}, 4^{\circ} \mathrm{N}$ was chosen in part to allow further comparison with Fig. 4, and, in Fig. 3b, $20^{\circ} \mathrm{N}$ was chosen to allow further comparison with the results from Beig et al. (2012) based on composite data in the $0-30^{\circ}$ latitude band. We note that our results show that there can be significant differences in responses at various latitudes.

Figure 4 shows ozone responses to solar activity versus altitude, from 50 to $100 \mathrm{~km}$, at the Equator for sunrise (Fig. 4a) and sunset (Fig. 4b). Values are responses at solar max minus those at solar min (\%/100 sfu). Red diamonds denote responses found by Beig et al. (2012) at 6LST (Fig. 4a) and $18 \mathrm{LST}$ (Fig. 4b), composite from $0-4^{\circ} \mathrm{N}$. Blue plusses denote our corresponding results based on SABER data. This 

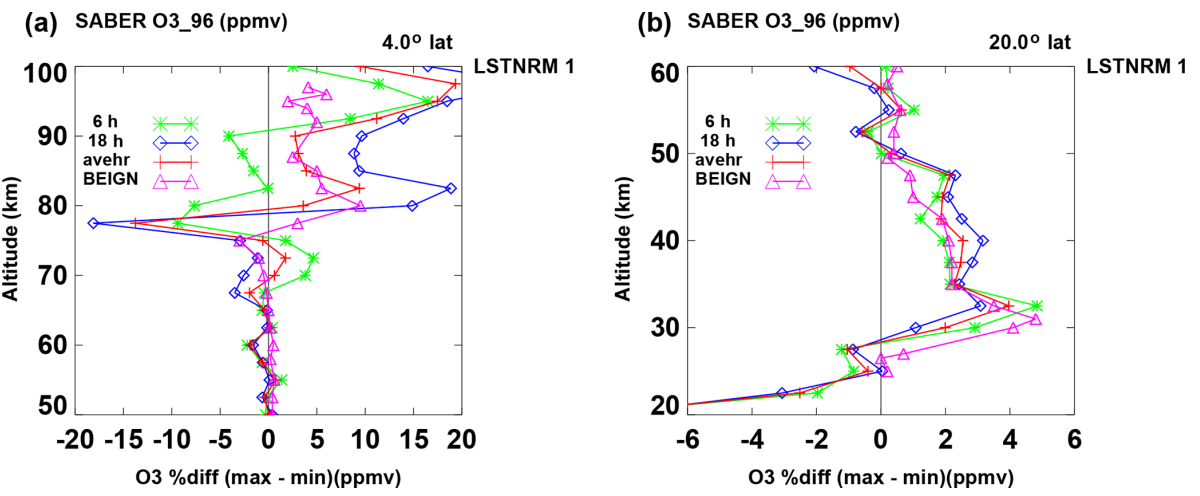

Figure 3. Ozone responses to the solar decadal cycle versus altitude at $4^{\circ} \mathrm{N}$ from 50 to $100 \mathrm{~km} \mathrm{(a),} \mathrm{and} \mathrm{at} 20^{\circ} \mathrm{N}$ from 20 to $60 \mathrm{~km}(\mathbf{b})$. Values are responses at solar max minus responses at solar min (\%/100 sfu). Magenta triangles denote the results from Beig et al. (2012), which are the average of responses at 6 and 18 LST (local time) and $0-30^{\circ} \mathrm{N}$; red plusses denote our estimate (average at 6 and 18 LST); green asterisks denote our estimate at $6 \mathrm{LST}$; and blue diamonds denote our estimate at $18 \mathrm{LST}$.

is the only instance where Beig et al. (2012) show responses separately for 6 and 18 LST.

Except for the large negative values (red diamonds) from Beig et al. (2012) in Fig. 4 a near 74 km, and the large negative value (blue plusses) from this study at $77.5 \mathrm{~km}$ in Fig. $4 \mathrm{~b}$, we believe that the comparisons are mostly favorable, in view of the uncertainties discussed earlier. Although not shown, the half width of the error bars provided by Beig et al. (2012) between 80 to $90 \mathrm{~km}$ are $\sim \pm 10 \% / 100 \mathrm{sfu}$.

This can be compared with our results in Fig. $3 \mathrm{a}$ at $4^{\circ} \mathrm{N}$. It is seen that although there are sharp variations above $70 \mathrm{~km}$, the agreements are at least qualitatively good, considering the caveats noted above.

The large excursions near $75 \mathrm{~km}$ are not isolated, but are systematic for both Beig et al. (2012) and the results from this study, as can also be seen in Fig. 6 at $16^{\circ} \mathrm{N}$.

\subsection{Temperature responses at 6 and 18 LST (sunrise and sunset)}

Figure 5 corresponds to Fig. 3, but for temperature. Values are responses at solar max minus responses at solar min (K/100 sfu).

Figure 5 a shows temperature responses from 50 to $100 \mathrm{~km}$, at $32^{\circ} \mathrm{N}$ from this study and from Beig et al. (2012). The magenta triangles show responses based on HALOE data, from Beig et al. (2012), for temperature (composite, $0-30^{\circ} \mathrm{N}$, BEIGN), which are averages of sunrise and sunset responses, and should be compared with the red plusses that denote the average of our results at 6 and 18LST. It can be seen that the agreement with our averages (magenta triangles and red plusses) is very favorable, except at $75 \mathrm{~km}$. Beig et al. (2012) do not provide temperature responses above $75 \mathrm{~km}$. The green asterisks denote our results for 6 LST, and the blue diamonds denote our responses at 18 LST. Beig et al. (2012) do not provide results separately for 6 and 18 LST.
Figure $5 \mathrm{~b}$ corresponds to Fig. $5 \mathrm{a}$, but for $16^{\circ} \mathrm{N}$ and 20 to $60 \mathrm{~km}$, and the HALOE results are from Fadnavis and Beig (2006), $0-30^{\circ} \mathrm{N}$ composite. Above $30 \mathrm{~km}$, the agreement with our averages (magenta triangles and red plusses) is very favorable. We note that according to Fadnivas and Beig (2006) and Remsberg et al. (2002), HALOE uses temperatures from the National Center for Environmental Prediction (NCEP) at altitudes below $\sim 35 \mathrm{~km}(\sim 5 \mathrm{hPa})$.

This could be the reason for the differences between the magenta triangles and our red plusses below $35 \mathrm{~km}$.

It can be seen that even in the stratosphere, the responses at $6 \mathrm{LST}$ are different from those at $18 \mathrm{LST}$. We note that Fig. 5a represents results at $32^{\circ} \mathrm{N}$, instead of $16^{\circ} \mathrm{N}$, as the agreement with results by Beig et al. (2012) is somewhat better.

\section{Ozone and temperature responses over a diurnal cycle}

In this section, we extend our results to other local times. Although the figures only show responses at $6,12,18$, and 24 LST, we have generated hourly responses, and can do so at any local time. We do not believe that plots at additional local times would add important information for the purpose of this paper, and would only make other details less discernible.

Generally, previous studies based on other satellite measurements do not describe how they treat data with respect to local times, and we cannot make comparisons as with HALOE. Some studies use different data from various instruments, which mix data measured at different local times. See Sect. 5.2 and the discussion in reference to Fig. 9, for details.

Figure 6 shows our ozone (Fig. 6a) and temperature (Fig. 6b) responses from 50 to $100 \mathrm{~km}$, at $16^{\circ} \mathrm{N}$ over a diurnal cycle $(6,12,18$, and 24 LST). The black line denotes our responses based on SABER data, where the zonal means 

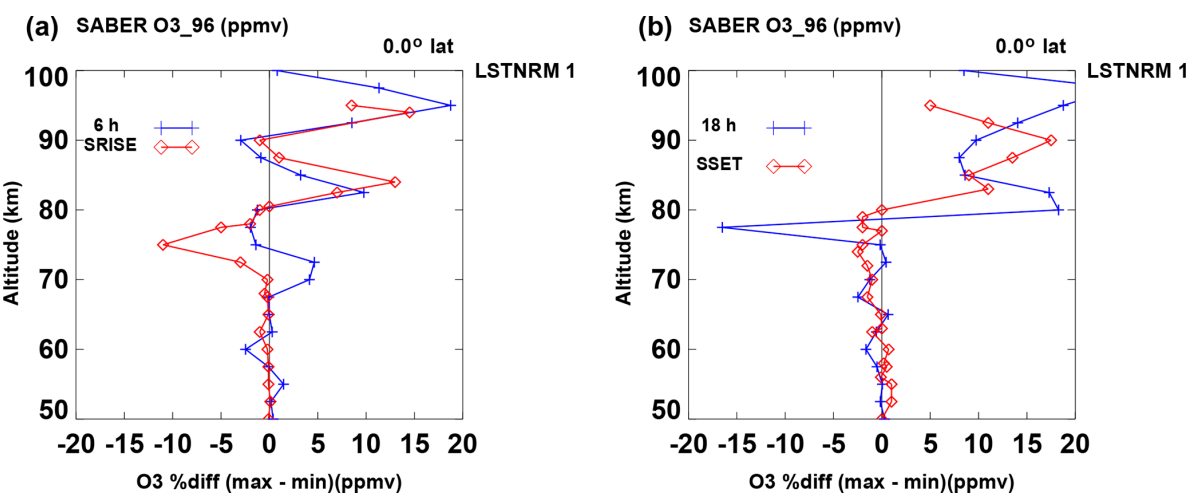

Figure 4. Ozone responses to solar activity versus altitude from 50 to $100 \mathrm{~km}$ at the Equator. Values are responses at solar max minus responses at solar min $(\% / 100 \mathrm{sfu})$. Red diamonds denote results based on HALOE data from Beig et al. (2012) at 6 LST (a) and 18 LST (b), composite from $0-4^{\circ} \mathrm{N}$. Blue plusses denote our results based on SABER data at 6 LST and $0^{\circ}$ (a) and 18 LST (b).
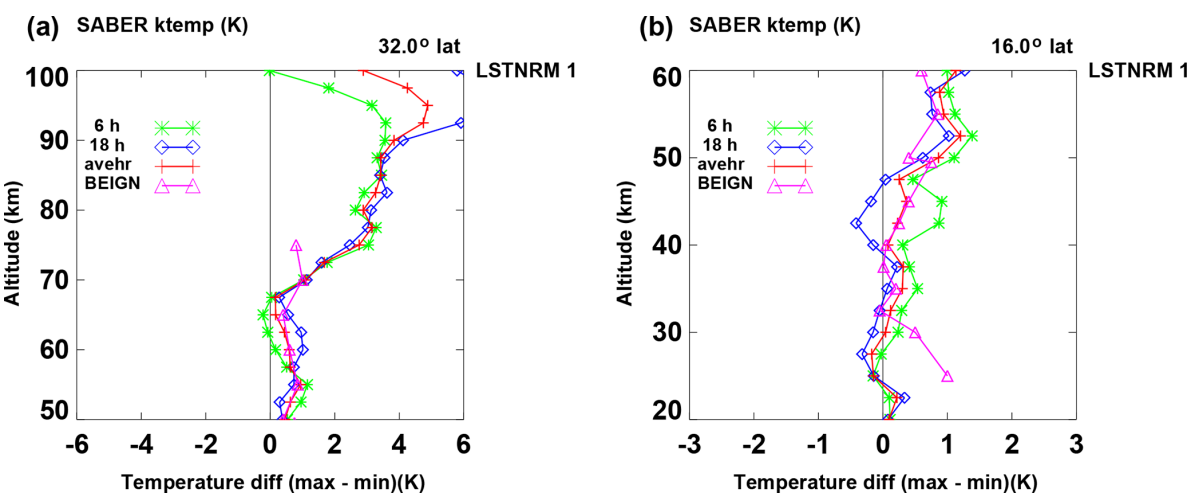

Figure 5. Corresponds to Fig. 3, but for temperature responses to solar activity versus altitude, from 50 to $100 \mathrm{~km}$ (a), and 20 to $60 \mathrm{~km}$ (b). Values are responses at solar max minus responses at solar min (K/100 sfu). Magenta triangles denote results by Beig et al. (2012), average of 6 and $18 \mathrm{LST}$ (composite $0-30^{\circ} \mathrm{N}$ ). Red plusses denote our estimate (average of 6 and $18 \mathrm{LST}$ at $32^{\circ} \mathrm{N}, \mathbf{a}$ and $16^{\circ} \mathrm{N}, \mathbf{b}$ ), based on SABER data. Green asterisks denote our estimates at 6 LST, and blue diamonds are estimates at $18 \mathrm{LST}$.

are averages over both longitude and a $24 \mathrm{~h}$ local time period. The green asterisks denote responses for $6 \mathrm{LST}$, blue diamonds represent $12 \mathrm{LST}$, red plusses represent $18 \mathrm{LST}$, and magenta triangles represent 24 LST.

Up until this point, ozone values are responses at solar max minus responses at solar min $(\% / 100 \mathrm{sfu})$. In the following, note that unlike the situation above at 6 and 18 LST for ozone, the normalizing values used to obtain responses in percent are now averaged over local time, to be consistent with responses based on zonal means that are averages over both longitude and local time (black line in Fig. 6).

Figure 7 shows the ozone (Fig. 7a) and temperature (Fig. 7b) responses to solar activity versus altitude at the Equator; from 20 to $60 \mathrm{~km}$, at $6 \mathrm{LST}$ (green asterisks), 12 LST (blue diamonds), 18 LST (red plusses), and 24 LST (magenta triangles); and based on zonal means that are averages over local times (black asterisks). For ozone, below about $40 \mathrm{~km}$, diurnal variations have relatively little effect on responses. For temperature, the effects can be larger, even at altitudes as low as $30 \mathrm{~km}$.
Figures A1 and A2 in the Appendix present plots corresponding to Fig. 7, but for 32 and $44^{\circ}$.

\section{Comparisons with responses based on operational satellite measurements (fixed or drifting local times)}

In the stratosphere and lower mesosphere, previous global results of responses to the decadal solar cycle have been largely based on data from the NOAA operational satellites, including the Stratosphere Sounding Unit (SSU), the Microwave Sounding Unit (MSU), and the Solar Backscatter Ultraviolet (SBUV) instruments. An advantage of the operational satellites is that they can provide global measurements covering decades, and can be replaced as the instruments degrade. However, issues of calibration, instrument offsets, stability, and continuity, can be problematic. The satellites are generally polar orbiters and sun-synchronous, and make measurements at two fixed local times, one for the satellite ascending mode, and one for the descending mode. 

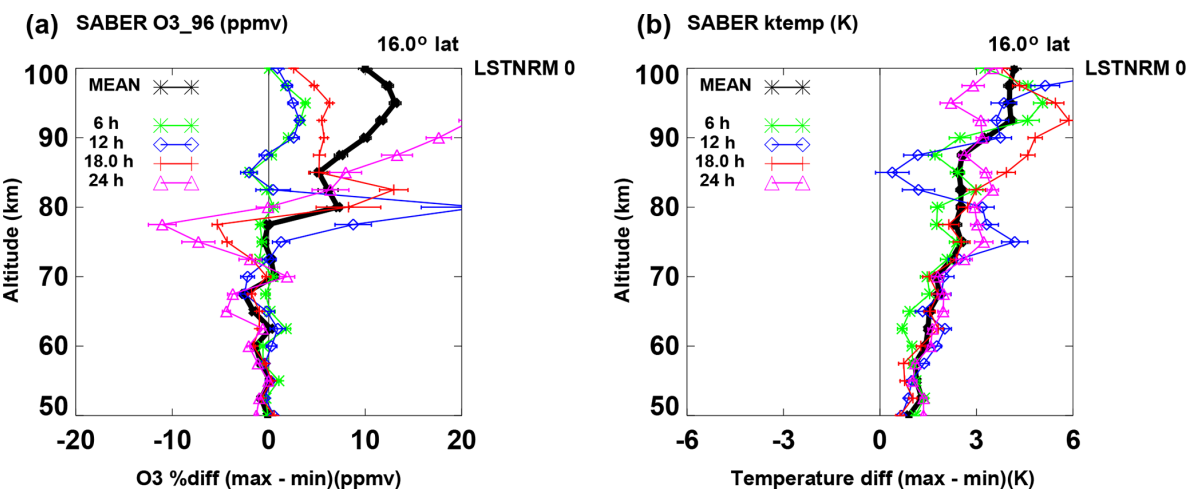

Figure 6. Ozone (a) and temperature (b) responses from 50 to $100 \mathrm{~km}$ at $16^{\circ} \mathrm{N}$. Values are responses at solar max minus responses at solar min for ozone $(\% / 100 \mathrm{sfu})$ and for temperature $(\mathrm{K} / 100 \mathrm{sfu})$. Black asterisks denote responses based on zonal means that are averages over both longitude and local time, green asterisks denote our responses based on zonal means fixed at 6 LST, blue diamonds represent zonal means fixed at $12 \mathrm{LST}$, red plusses represent zonal means fixed at $18 \mathrm{LST}$, and magenta triangles represent zonal means fixed at $24 \mathrm{LST}$, based on SABER data.
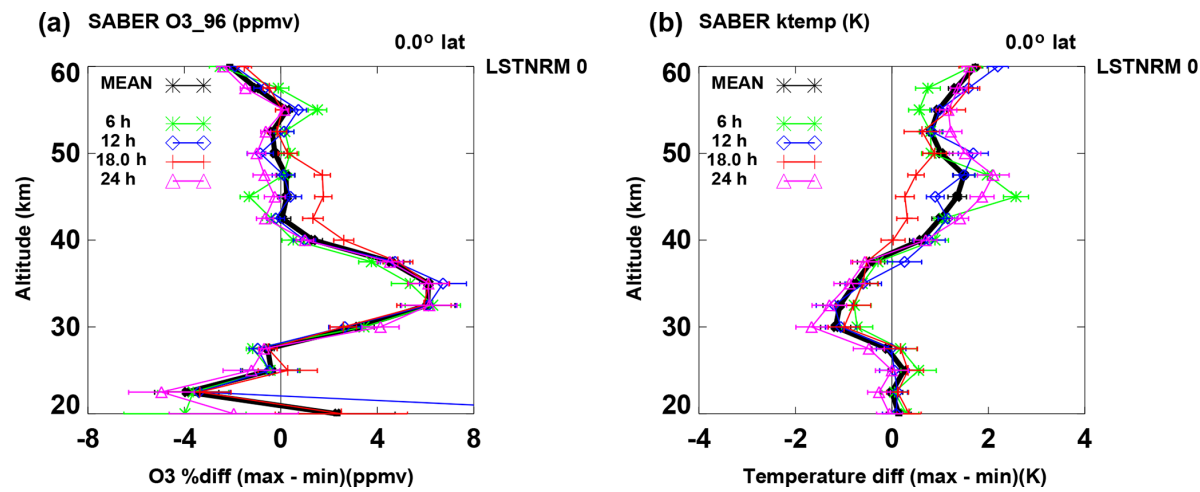

Figure 7. As in Fig. 6, but from 20 to $60 \mathrm{~km}$. Ozone (a) and temperature (b) responses at $0^{\circ}$. Values are responses at solar max minus responses at solar min for ozone $(\% / 100 \mathrm{sfu})$ and for temperature $(\mathrm{K} / 100 \mathrm{sfu})$. Black asterisks denote our responses based on zonal means that are averages over both longitude and local time; green asterisks denote our responses of zonal means at 6 LST, blue diamonds represent responses of zonal means at $12 \mathrm{LST}$, red plusses represent responses of zonal means at $18 \mathrm{LST}$, and magenta triangles represent responses of zonal means at $24 \mathrm{LST}$, based on SABER data.

As noted above, in merging data from different satellites, consistency in local times needs to be considered. Tummon et al. (2015), in reviewing some of the data processing methods used by various groups, report that diurnal variations are generally either neglected or are assumed to be negligible below $\sim 45-50 \mathrm{~km}$ (see also Davis et al., 2016).

\subsection{Effects of local time variations due to satellite orbital drift}

As noted earlier, over years, the orbits of some satellites have drifted, so that the local times at which measurements are made have also drifted by several hours, as described by McPeters et al. (2013).

To study the effects of local time changes due to orbital drift, from our estimates of diurnal variations, we can simulate their effects on responses to solar variability. As a simple example, Fig. 8 shows our results for ozone (Fig. 8a) and temperature (Fig. 8b) responses to solar activity versus altitude, at the Equator, from 20 to $60 \mathrm{~km}$. Values are responses at solar max minus responses at solar min in percent per $100 \mathrm{sfu}$ for ozone, and Kelvin per $100 \mathrm{sfu}$ for temperature. The red squares denote results where local times increased linearly from 12 to 18 LST from 2002 to 2014, to simulate orbital drift. Black asterisks denote responses based on zonal means that are averages over both longitude and local time. It can be seen that there are significant differences between them, especially above $40 \mathrm{~km}$. We have also run tests with the local time varying at different hours and durations, and the differences can be smaller or more pronounced than those shown in Fig. 8.

\subsection{Comparisons with operational satellite data}

Unlike the above comparisons with results from Beig et al. (2012), based on HALOE data, other studies, such as 

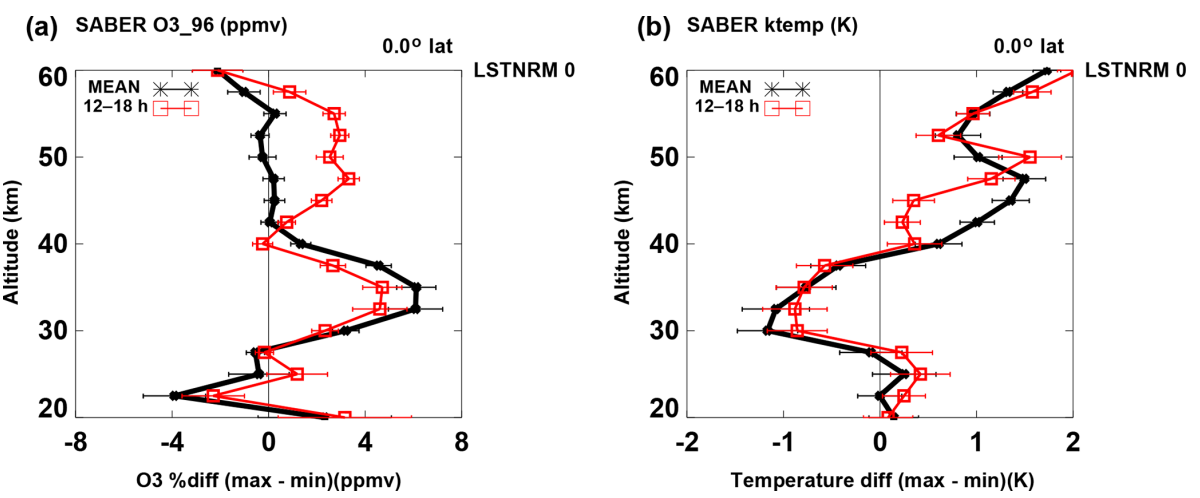

Figure 8. Ozone (a) and temperature (b) responses to solar activity versus altitude at the Equator from 20 to $60 \mathrm{~km}$. Values are responses at solar max minus responses at solar min in percent per 100 sfu for ozone, and Kelvin per 100 sfu for temperature. Black asterisks denote responses based on zonal means that are averages over both longitude and local time. Red squares denote corresponding results, but with local times increasing linearly from 12 to 18 LST from 2002 to 2014.

those based on operational satellites, generally have not described in detail how they approached the issue of diurnal variations. Hence, we will not attempt to make comparisons, and will only present some previous findings. In addition to issues related to local times, there have been reports based on data-related issues in general. Details can be found in Austin et al. (2008), Crooks and Gray (2005), Gray et al. (2005), and Huang et al. (2016b).

Figure 9 is taken from our previous analysis (Huang et al., 2016b, Fig. 3). It compares results from previous studies undertaken by others, which were manually transferred by us, and are therefore not exact. Our ozone responses (black line, SABER) are shown in Fig. 9a, versus altitude from 20 to $60 \mathrm{~km}$, averaged from $24^{\circ} \mathrm{S}$ to $24^{\circ} \mathrm{N}$, to better conform to results from others. The light blue squares represent results from Remsberg (2008, RMSBRG), the green asterisks are results from Fadnavis and Beig (2006, BEIGN, $0-30^{\circ} \mathrm{N}$ ), and the blue diamonds are results from Beig et al. (2012, BEIGS, $0-30^{\circ} \mathrm{S}$ ), which are all based on HALOE data.

The red line (plusses) in Fig. 9a shows ozone responses from Soukharev and Hood (2006) (AUDTA, data from 1979 to 2003), as reported by Austin et al. (2008), and from models (AUMDL, magenta lines and triangles), which were also reported by Austin et al. (2008), representing composite results from $25^{\circ} \mathrm{S}$ to $25^{\circ} \mathrm{N}$ latitude. The Soukharev and Hood (2006) results (red plusses) are a composite based on SBUV, HALOE, and SAGE data, which show a minimum near $30 \mathrm{~km}$, and a maximum above $40 \mathrm{~km}$.

Figure $9 \mathrm{~b}$ corresponds to the Fig. 9a, but for temperature. The temperature responses (AUDTA, data from 1979 to 1997) were taken by Austin et al. (2008) from Scaife et al. (2000). In Fig. 9b, the black line denotes our responses based on SABER data, averaged from $24^{\circ} \mathrm{S}$ to $24^{\circ} \mathrm{N}$, to conform to previous results by others.

The issue of local time effects is not discussed in detail in these studies. As noted above, Austin et al. (2008) note that zonal means of models are averages over local time in contrast to those based on satellite measurements, which are typically at fixed local times.

Nath and Sridharan (2014) also analyzed the same SABER data as we did and derived responses at a latitude of $10-15^{\circ}$. Plots comparing the results from both studies are given in Fig. 10 (taken from Fig. 5 of Huang et al., 2016a): black lines denote our results, and red asterisks denote those from Nath and Sridharan (2014). For both ozone and temperature, their responses agree better with ours up to $\sim 45 \mathrm{~km}$, but not so well at higher altitudes. We believe that the differences of the responses at higher altitudes are due to the local time variations in the SABER data, as discussed in Sect. 2. Nath and Sridharan (2014) do not appear to have considered diurnal variations. Note that in Fig. 10 the ozone responses are not in percent differences, as in other plots, so that differences between 45 and $80 \mathrm{~km}$ are not readily discernible, due to their small values.

\section{Data length and aliasing}

In Sect. 2.2.2, we noted that in the application of Eq. (1), possible aliasing among the different terms is not definitively addressed. In addition, it has been argued that more than one solar cycle of data is more advantageous. Following our analysis given in Huang et al. (2016b), we address these issues in this section.

Figure 11 is a scatterplot of monthly values versus the $10.7 \mathrm{~cm}$ flux. Figure $11 \mathrm{a}$ and $\mathrm{b}$ show ozone at $47.5 \mathrm{~km}$ at the Equator, whereas Fig. $11 \mathrm{c}$ and d show temperature at $45 \mathrm{~km}$ at the Equator. Figure 11a and c represent the monthly zonal means that are averaged over both longitude and local time, and Fig. 11b and d use zonal means where the local times simulate orbital drift as discussed in reference to Fig. 8. The red lines in Fig. 11 represent linear fits between the monthly values and the $10.7 \mathrm{~cm}$ flux, which corresponds to using only the solar term (F107) of the multiple regression (Eq. 1). For 

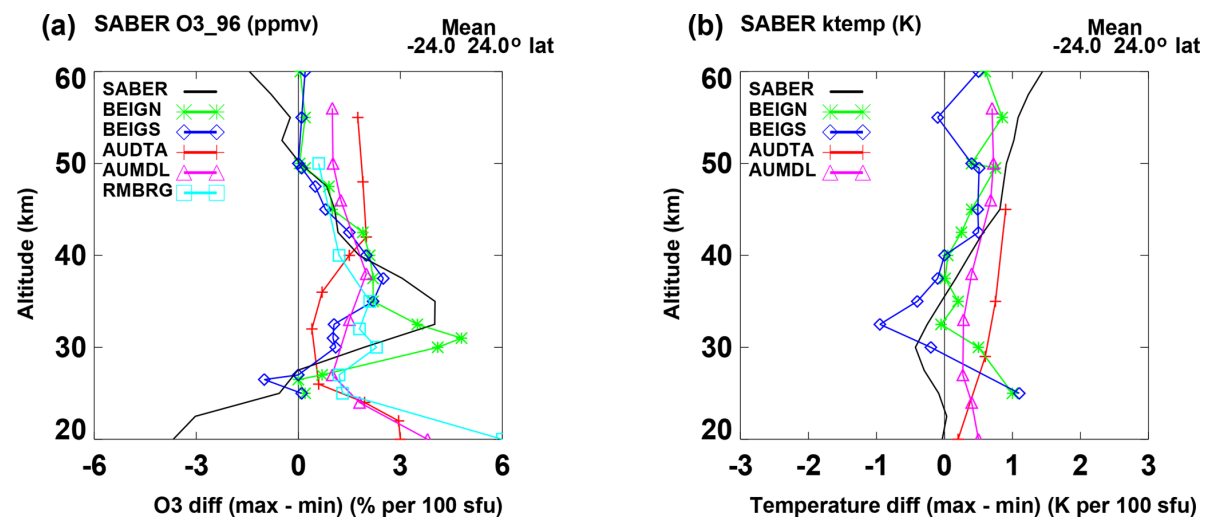

Figure 9. (a) Ozone responses versus altitude from 20 to $60 \mathrm{~km}$. The black line represents SABER results averaged from $24^{\circ} \mathrm{S}$ to $24^{\circ} \mathrm{N}$; the light blue squares denote results from Remsberg (2008, RMSBRG); the green asterisks represent Fadnavis and Beig (2006), BEIGN, $0-30^{\circ} \mathrm{N}$; the blue diamonds represent BEIGS, 0-30 $\mathrm{S}$, HALOE data; the red plusses denote results from Austin et al. (2008) data AUDTA; the magenta triangles represents the Austin et al. (2008) model, AUMDL, $25^{\circ} \mathrm{S}$ to $25^{\circ} \mathrm{N}$ latitude composite. (b) Temperature responses corresponding to (a).
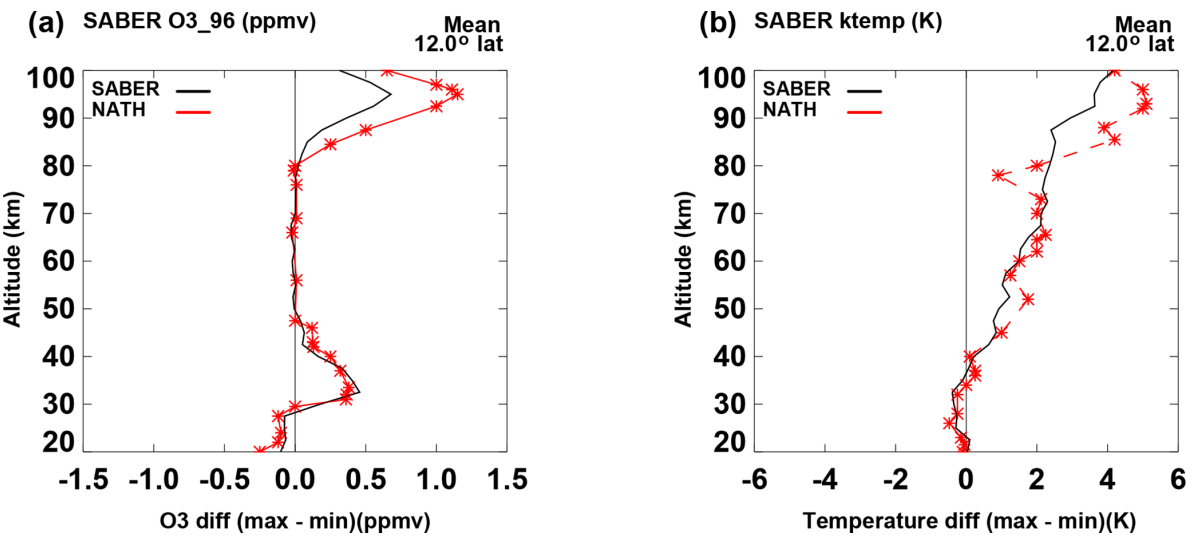

Figure 10. Ozone (a) and temperature (b) responses to solar activity versus altitude from 20 to $100 \mathrm{~km}$. Values are responses at solar max minus responses at solar min (in parts per million by volume per 100 sfu for ozone and Kelvin per 100 sfu for temperature). Black lines denote SABER responses at $12^{\circ}$ latitude; red lines denote results from Nath and Sridharan (2014) for a latitude of $10-15^{\circ}$, also based on SABER data.

ozone (Fig. 11a, b), the values $0.28 \% / 100$ sfu (Fig. 11a, topleft label) and $3.24 \% / 100 \mathrm{sfu}$ at $47.5 \mathrm{~km}$ (Fig. 11b, top-left label) compare well with the regression results which use all of the terms of Eq. (1), seen in Fig. 8a. For temperature (Fig. $11 \mathrm{c}$, d), the values $1.23 \mathrm{~K} / 100 \mathrm{sfu}$ and $0.32 \mathrm{~K} / 100 \mathrm{sfu}$ at $45 \mathrm{~km}$ also compare well with Fig. 8b. Consequently, aliasing from other terms in Eq. (1) is not significant.

As for issues of data length, unlike time series data, where time increases monotonically with data length, the $10.7 \mathrm{~cm}$ flux values remain within a fixed interval between solar minimum and solar maximum ( 70 and $200 \mathrm{sfu})$. In Fig. 11, the values span about one solar cycle. However, even over more solar cycles, the $10.7 \mathrm{~cm}$ flux values would only repeat and backfill in with values in the same general area in Fig. 11, effectively providing a more average result but not necessarily reducing the uncertainty much otherwise.
It can be argued that even with more than one solar cycle of data available, analysis over individual cycles should be carried out to analyze differences among solar cycles.

\section{Summary and discussion}

Using SABER data, we investigated the effects of ozone and temperature diurnal variations on their responses to the solar cycle, from 2002 to 2014 and 20 to $100 \mathrm{~km}$.

We find that for ozone, above $\sim 40 \mathrm{~km}$, zonal means reflecting specific local times (e.g., 6, 12, 18, and 24 LST) lead to different values of responses compared to each other, and compared to responses based on zonal means that are averaged over the $24 \mathrm{~h}$ local time period (Figs. 6, 7). For temperature, effects of diurnal variations are not negligible at $\sim 30 \mathrm{~km}$ and above. 

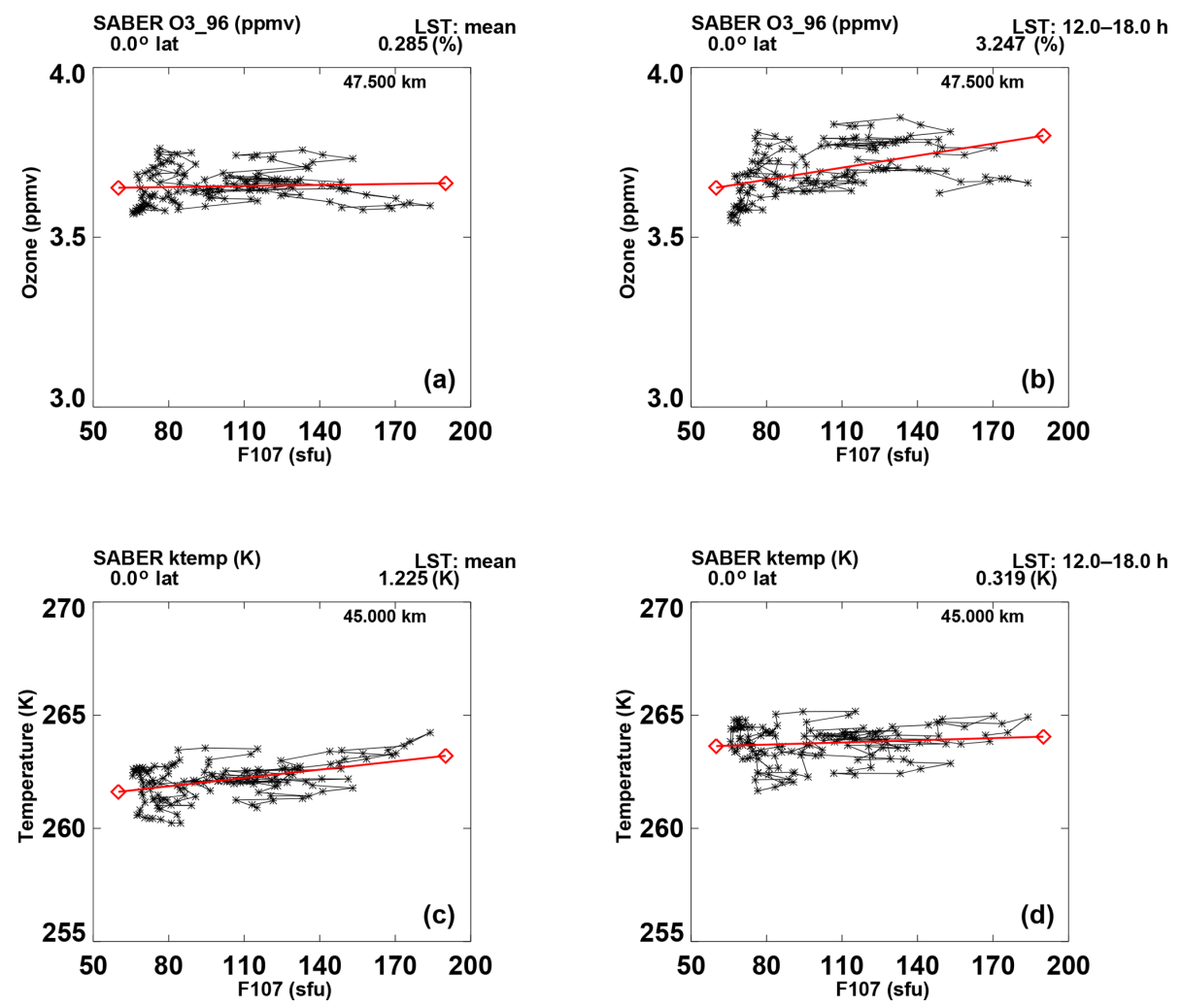

Figure 11. (a, b) Scatterplot of ozone monthly values versus $10.7 \mathrm{~cm}$ flux (sfu) at $47.5 \mathrm{~km}$ and the Equator. (a, c) Monthly values are zonal means, including the average over local time. (b, d) As in (a) and (c), but zonal means include simulated local time variations of orbital drift. (c, d) As in (a) and (b), but for temperature monthly values. Red lines represent the linear fit between monthly values and $10.7 \mathrm{~cm}$ flux. Compare with Fig. 8.

We also considered the variations of local times themselves due to orbital drifts of certain operational satellites, and their effects on responses to the solar cycle (Fig. 8). The differences can be significant above $\sim 35 \mathrm{~km}$.

The quality and validity of our analysis are shown in comparisons with responses found by Beig et al. (2012) and Fadnavis and Beig (2006), based on HALOE data, which made measurements only at sunrise and sunset. Comparisons with our corresponding results, based on SABER measurements, are favorable, both at sunrise and sunset separately, and combined. Our analysis is robust in that the average of responses at specific local times over a diurnal period of $24 \mathrm{~h}$ is the same as responses based on zonal means that are averages over longitude and local time together.

Previous studies based on other satellite data generally do not describe the treatment, if any, of local times, so we cannot compare our data with their studies as we have with HALOE data. Some studies also analyzed data merged from different sources, with measurements made at different local times. As discussed in Sect. 5.2 in reference to Fig. 9, the results of these studies do not generally agree very well among themselves.
We do not believe that diurnal variations are the major reason for the discrepancies, as there are likely other data-related issues. Other reasons for differences may be the conditions and constraints under which the various measurements were made. Details can be found in Austin et al. (2008), Crooks and Gray (2005), Gray et al. (2005), and Huang et al. (2016b). However, diurnal variations should be included as part of the analysis of the differences among various results.

The effects due to satellite orbital drift (discussion in reference to Fig. 8) may explain some unexpected variations in the responses, especially above $40 \mathrm{~km}$.

Data availability. The SABER data are freely available from the SABER project at http://saber.gats-inc.com/ (last access: June 2016). 


\section{Appendix A}
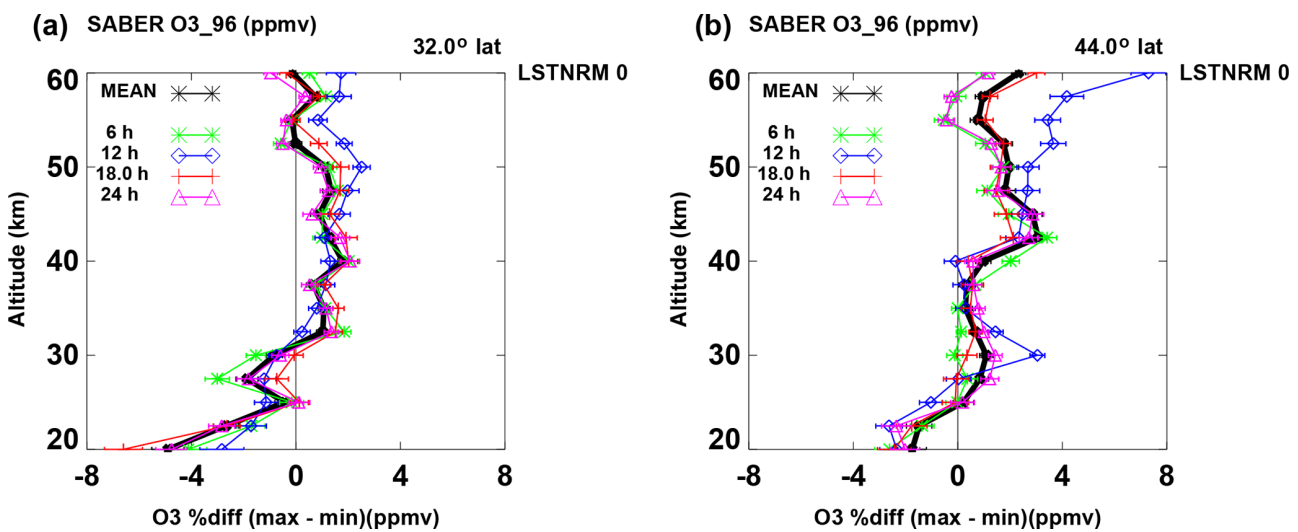

Figure A1. As in Fig. 7, ozone responses at $32^{\circ}$ (a) and $44^{\circ}$ from 20 to $60 \mathrm{~km}$. Values are responses at solar max minus responses at solar min $(\% / 100 \mathrm{sfu})$. Black asterisks denote our responses based on zonal means that are averages over both longitude and local time. Green asterisks denote our responses of zonal means at $6 \mathrm{LST}$, blue diamonds denote our responses of zonal means at 12 LST, red plusses denote our responses of zonal means at $18 \mathrm{LST}$, and magenta triangles denote our responses of zonal means at $24 \mathrm{LST}$, based on SABER data.
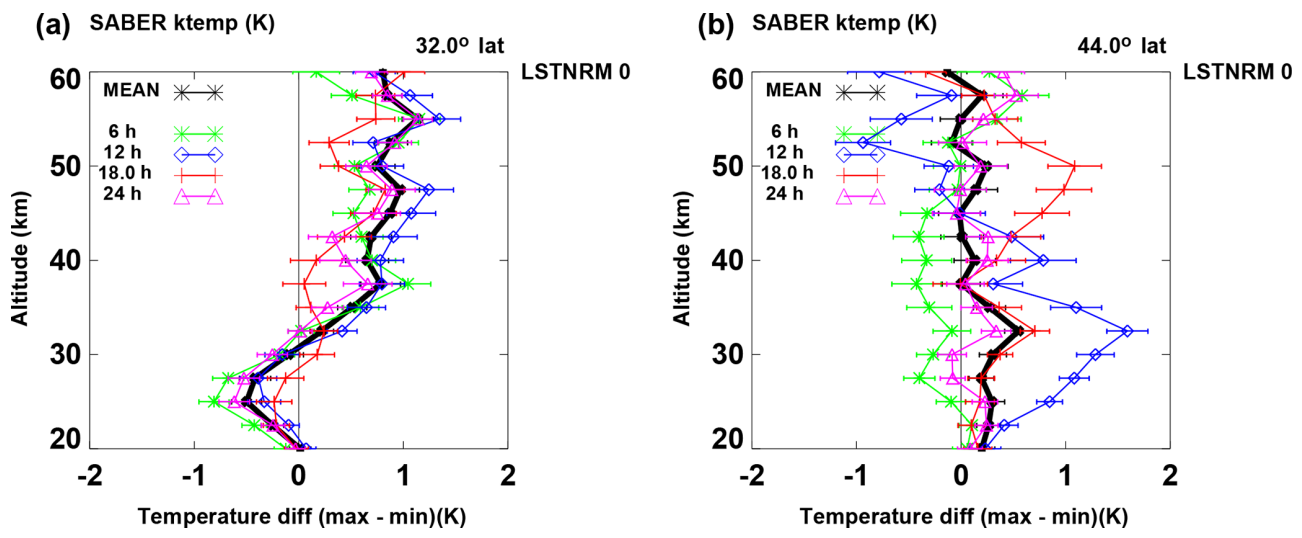

Figure A2. As in Fig. A1, but for temperature responses at $32^{\circ}$ (a) and $44^{\circ}$ from 20 to $60 \mathrm{~km}$. Values are responses at solar max minus responses at solar min $(\mathrm{K} / 100 \mathrm{sfu})$. Black asterisks denote our responses based on zonal means that are averages over both longitude and local time. Green asterisks denote our responses of zonal means at 6LST, blue diamonds denote our responses of zonal means at 12 LST, red plusses denote our responses of zonal means at $18 \mathrm{LST}$, and magenta triangles denote our responses of zonal means at $24 \mathrm{LST}$, based on SABER data. 
Author contributions. This research focuses on SABER/TIMED measurements. HM is a Principal Investigator (PI) on the TIMED project, and has contributed over the years to theoretical and empirical interpretations of influences of solar variability to the atmosphere. FH focused on the data analysis and interpretation of results.

Competing interests. The authors declare that they have no conflict of interest.

Acknowledgements. We thank the editors Petr Pisoft, Christoph Jacobi, and two anonymous reviewers, whose comments helped improve the paper.

Review statement. This paper was edited by Petr Pisoft and reviewed by Jan Laštovička and two anonymous referees.

\section{References}

Austin, J., Tourpali, K., Rozanov, E., Akiyoshi, H., Bekki, S., Bodeker, G., Brühl, C., Butchart, N, Chipperfield, M., Deushi, M., Fomichev, V. I., Giorgetta, M. A., Gray, L., Kodera, K., Lott, F., Manzini, E., Marsh, D., Matthes, K., Nagashima, T., Shibata, K., Stolarski, R. S., Struthers, H., and Tian, W.: Coupled chemistry climate model simulations of the solar cycle in ozone and temperature, J. Geophys. Res., 113, D11306, https://doi.org/10.1029/2007JD009391, 2008

Beig, G., Fadnavis, S., Schmidt, H., and Brasseur, G. P.: Intercomparison of 11-year solar cycle response in mesospheric ozone and temperature obtained by HALOE satellite data and HAMMONIA model, J. Geophys Res., 117, D00P10, https://doi.org/10.1029/2011JD015697, 2012.

Bevington, P. R. and Robinson, D. K.,: Data reduction and error analysis for the physical sciences, McGraw-Hill, New York, USA, 1992.

Brasseur, G. P. and Solomon, S.: Aeronomy of the Middle Atmosphere, Springer, Dordrecht, the Netherlands, 2005.

Chapman, S. and Lindzen, R. S.: Atmospheric Tides, Springer, New York, 1970.

Crooks, S. A. and Gray, L. J.: Characterization of the 11-year solar signal using multiple regression analysis of the ERA-40 dataset, J. Climate, 18, 996-1015, 2005.

Davis, S. M., Rosenlof, K. H., Hassler, B., Hurst, D. F., Read, W. G., Vömel, H., Selkirk, H., Fujiwara, M., and Damadeo, R.: The Stratospheric Water and Ozone Satellite Homogenized (SWOOSH) database: a long-term database for climate studies, Earth Syst. Sci. Data, 8, 461-490, https://doi.org/10.5194/essd-8461-2016, 2016.

Fadnavis, S. and Beig, G.: Decadal solar effects on temperature and ozone in the tropical stratosphere, Ann. Geophys., 24, 20912103, https://doi.org/10.5194/angeo-24-2091-2006, 2006.

Frith, S. M., Kramarova, N. A., Stolarski, R. S., McPeters, R. D., Bhartia, P. K., and Labow, G. J.: Recent changes in column ozone based on the SBUV version 8.6 merged ozone dataset, J. Geophys. Res.-Atmos., 119, 9735-9751, https://doi.org/10.1002/2014JD021889, 2014.
Gille, S. T., Hauchecorne, A., and Chanin, M.-L.: Semidiurnal and diurnal tidal effects in the middle atmosphere as seen by Rayleigh lidar, J. Geophys. Res., 96, 7579-7587, 1991.

Gray, L. J., Haigh, J. D., and Harrison, R. G.: A Review of The Influence of Solar Changes on the Earth's Climate, Hadley Centre technical note 62, 1-81, University of Reading, Reading, 2005.

Hood, L. L., Misios, S., Mitchell, D. M., Rozanov, E., Gray, L. J., Tourpali, K., Matthes, K., Schmidt, H., Chiodo, G., Thiéblemont, R., Shindell, D., and Krivolutsky, A.: Solar Signals in CMIP-5 Simulations: The Ozone Response, Q. J. Roy. Meteor. Soc., 141, 2670-2689, https://doi.org/10.1002/qj.2553, 2015.

Huang, F. T., Mayr, H. G., Reber, C. A., Russell III, J. M., Mlynczak, M. G., and Mengel, J. G.: Ozone quasi-biennial oscillations (QBO), semiannual oscillations (SAO), and correlations with temperature in the mesosphere, lower thermosphere, and stratosphere, based on measurements from SABER on TIMED and MLS on UARS, J. Geophys. Res., 113, A01316, https://doi.org/10.1029/2007JA012634, 2008a.

Huang, F. T., Mayr, H. G., Russell III, J. M., Mlynczak, M. G., and Reber, C. A.: Ozone diurnal variations and mean profiles in the mesosphere, lower thermosphere, and stratosphere, based on measurements from SABER on TIMED, J. Geophys. Res., 113, A04307, https://doi.org/10.1029/2007JA012739, 2008b.

Huang, F. T., McPeters, R. D., Bhartia, P. K., Mayr, H. G., Frith, S. M., Russell III, J. M., and Mlynczak, M. G.: Temperature diurnal variations (migrating tides) in the stratosphere and lower mesosphere based on measurements from SABER on TIMED, J. Geophys. Res., 115, D16121, https://doi.org/10.1029/2009JD013698, 2010a.

Huang, F. T., Mayr, H. G., Russell III, J. M., and Mlynczak, M. G.: Ozone diurnal variations in the stratosphere and lower mesosphere, based on measurements from SABER on TIMED, J. Geophys. Res., 115, D24308, https://doi.org/10.1029/2010JD014484, 2010b.

Huang, F. T., Mayr, H. G., Russell III, J. M., and Mlynczak, M. G.: Ozone and temperature decadal trends in the stratosphere, mesosphere and lower thermosphere, based on measurements from SABER on TIMED, Ann. Geophys., 32, 935-949, https://doi.org/10.5194/angeo-32-935-2014, 2014.

Huang, F. T., Mayr, H. G., Russell III, J. M., and Mlynczak, M. G.: Ozone and temperature decadal responses to solar variability in the mesosphere and lower thermosphere, based on measurements from SABER on TIMED, Ann. Geophys., 34, 29-40, https://doi.org/10.5194/angeo-34-29-2016, $2016 \mathrm{a}$.

Huang, F. T., Mayr, H. G., Russell III, J. M., and Mlynczak, M. G.: Ozone and temperature decadal responses to solar variability in the stratosphere and lower mesosphere, based on measurements from SABER on TIMED, Ann. Geophys., 34, 801-813, https://doi.org/10.5194/angeo-34-801-2016, $2016 \mathrm{~b}$.

Keckhut, P., Cagnazzo, C., Chanin, M.-L., Claud, C., and Hauchecorne, A.: The 11-year solar-cycle effects on the temperature in the upper-stratosphere and mesosphere: Part I - Assessment of observations, J. Atmos. Sol.-Terr. Phy., 67, 940-947, 2005.

McPeters, R. D., Bhartia, P. K., Haffner, D., Labow, G. J., and Flynn, L.: The version 8.6 SBUV ozone data record: An overview, J. Geophys. Res.-Atmos., 118, 8032-8039, https://doi.org/10.1002/jgrd.50597, 2013. 
Mukhtarov, P., Pancheva, D., and Andonov, B.: Global structure and seasonal and interannual variability of the migrating diurnal tide seen in the SABER/TIMED temperatures between 20 and $120 \mathrm{~km}$, J. Geophys. Res., 114, A02309, https://doi.org/10.1029/2008JA013759, 2009.

Nath, O. and Sridharan, S.: Long-term variabilities and tendencies in zonal mean TIMED-SABER ozone and temperature in the middle atmosphere at $10-15^{\circ}$ N, J. Atmos. Sol.-Terr. Phy., 120, $1-8,2014$.

Oberheide, J., Hagan, M. E., Ward, W. E., Riese, M., and Offermann, D.: Modeling the diurnal tide for the Cryogenic Infrared Spectrometers and Telescopes for the Atmosphere (CRISTA) 1 time period, J. Geophys. Res., 105, 24917-24929, 2000.

Randel, W. J., Shine, K. P., Austin, J., Barnett, J.. Claud, C., Gillett, N. P., Keckhut, P., Langematz, U., Lin, R., Long, C., Mears, C., Miller, A., Nash, J., Seidel, D. J., Thompson, D. W. J., Wu, F., and Yoden, S.: An update of observed stratospheric temperature trends, J. Geophys. Res., 114, D02107, https://doi.org/10.1029/2008JD010421, 2009.

Remsberg, E. E.: On the response of Halogen Occultation Experiment (HALOE) stratospheric ozone and temperature to the 11-year solar cycle forcing, J. Geophys. Res., 113, D22304, https://doi.org/10.1029/2008JD010189, 2008.

Remsberg, E. E., Bhat, P. P., and Deaver, L. E.: Seasonal and long-term variations in middle atmosphere temperature from HALOE on UARS, J. Geophys. Res., 107, 4411, https://doi.org/10.1029/2001JD001366, 2002.

Russell III, J. M., Mlynczak, M. G., Gordley, L. L., Tansock, J., and Esplin, R.: An overview of the SABER experiment and preliminary calibration results, Proceedings of the SPIE, 44th Annual Meeting, 18-23 July, Denver, Colorado, 3756, 277-288, 1999.

Sakazaki, T., Fujiwara, M., Mitsuda, C., Imai, K., Manago, N., Naito, Y., Nakamura, T., Akiyoshi, H., Kinnison, D., Sano, T., Suzuki, M., and Shiotani, M.: Diurnal ozone variations in the stratosphere revealed in observations from the Superconducting Submillimeter-Wave Limb-Emission Sounder (SMILES) on board the International Space Station (ISS), J. Geophys. Res.Atmos., 118, 2991-3006, https://doi.org/10.1002/jgrd.50220, 2013.
Sakazaki, T., Shiotani, M., Suzuki, M., Kinnison, D., Zawodny, J. M., McHugh, M., and Walker, K. A.: Sunset-sunrise difference in solar occultation ozone measurements (SAGE II, HALOE, and ACE-FTS) and its relationship to tidal vertical winds, Atmos. Chem. Phys., 15, 829-843, https://doi.org/10.5194/acp-15-8292015, 2015.

Scaife, A. A., Austin, J., Butchart, N., Keil, M., Pawson, S., Nash, J., and James, I. N.: Seasonal and interannual variability of the stratosphere diagnosed from UKMO TOVS analyses, Q. J. Roy. Meteor. Soc., 126, 2585-2604, 2000.

Soukharev, B. E. and Hood, L. L.: The solar cycle variation of stratospheric ozone: Multiple regression analysis of long-term satellite data sets and comparisons with models, J. Geophys. Res., 111, D20314, https://doi.org/10.1029/2006JD007107, 2006.

Tummon, F., Hassler, B., Harris, N. R. P., Staehelin, J., Steinbrecht, W., Anderson, J., Bodeker, G. E., Bourassa, A., Davis, S. M., Degenstein, D., Frith, S. M., Froidevaux, L., Kyrölä, E., Laine, M., Long, C., Penckwitt, A. A., Sioris, C. E., Rosenlof, K. H., Roth, C., Wang, H.-J., and Wild, J.: Intercomparison of vertically resolved merged satellite ozone data sets: interannual variability and long-term trends, Atmos. Chem. Phys., 15, 3021-3043, https://doi.org/10.5194/acp-15-3021-2015, 2015.

Zeng, Z., Randel, W., Sokolovskiy, S., Deser, C., Kuo, Y.H., Hagan, M., Du, J., and Ward, W.: Detection of migrating diurnal tide in the tropical upper troposphere and lower stratosphere using the Challenging Minisatellite Payload radio occultation data, J. Geophys. Res., 113, D03102, https://doi.org/10.1029/2007JD008725, 2008.

Zhang, X., Forbes, J. M., Hagan, M. E., Russell III, J. M., Palo, S. E., Mertens, C. J., and Mlynczak, M. G.: Monthly tidal temperatures 20-120 km from TIMED/SABER, J. Geophys. Res., 111, A10S08, https://doi.org/10.1029/2005JA011504, 2006. 